\title{
Prediction of Banking Systemic Risk Based on Support Vector Machine
}

\author{
Shouwei Li, Mingliang Wang, and Jianmin He \\ School of Economics and Management, Southeast University, Nanjing, Jiangsu 211189, China \\ Correspondence should be addressed to Shouwei Li; lswseu@126.com
}

Received 1 February 2013; Accepted 22 April 2013

Academic Editor: Wei-Chiang Hong

Copyright (C) 2013 Shouwei Li et al. This is an open access article distributed under the Creative Commons Attribution License, which permits unrestricted use, distribution, and reproduction in any medium, provided the original work is properly cited.

\begin{abstract}
Banking systemic risk is a complex nonlinear phenomenon and has shed light on the importance of safeguarding financial stability by recent financial crisis. According to the complex nonlinear characteristics of banking systemic risk, in this paper we apply support vector machine (SVM) to the prediction of banking systemic risk in an attempt to suggest a new model with better explanatory power and stability. We conduct a case study of an SVM-based prediction model for Chinese banking systemic risk and find the experiment results showing that support vector machine is an efficient method in such case.
\end{abstract}

\section{Introduction}

Financial crises occurred over the past decade have shown that banking crises are usually in the core position of financial crises. Therefore, banking sectors' stability is a key to maintain financial stability. However, the major threat to banking sectors is systemic risk, because its contagion effect makes a single bank crisis evolve into the whole banking crisis, which may cause a financial crisis. The 2007-2009 financial crisis has threatened the stability of the international monetary market, shed light on the importance of systemic risk, and revealed the necessity of predicting one in order to safeguard financial stability.

The prediction of banking systemic crisis has been done since the mid-1990s. Frankel and Rose [1] use a probit model to evaluate the predictive power of several indicators for studying the determinants of currency crashes. Kaminsky and Reinhart [2] extend the analysis of Frankel and Rose [1] to a wider set of crises by introducing the so-called "signal" approach to evaluate the leading properties of indicators. Based on the study of Kaminsky and Reinhart [2], DemirgüçKunt and Detragiache [3] use a multivariate logit model for the prediction of banking crises. Other approaches are introduced to early warning models for systemic risk in the subsequent years, such as the regression model [4-6], the neurofuzzy approach [7], binary recursive trees $[8,9]$, and the alternative approach $[10,11]$.

In fact, banking systemic risk is a complex nonlinear phenomenon, which originates from diversity and uncertainty of risk sources, multiple contagion channels and their relationships as well as complexity and evolution of banking system structures [12-14]. The above prediction approaches either have certain limitations to analyze the complex nonlinear property of banking systemic risk or need a lot of samples. Recently, support vector machine (SVM) introduced by Vapnik [15] has become a promising tool for solving nonlinear regression problems and has been applied in prediction in many areas [16-18]. SVM has many advantages; for example, it combines the advantages of multivariate nonlinear regression in that only a small amount of data is required to produce a good generalization. In addition, the weakness of the transformational models in multivariate nonlinear regression can be overcome by mapping the data points to a sufficiently high-dimensional feature space [17]. Therefore, it is believed that SVM will provide a new approach for predicting banking systemic risk.

In this paper, we attempt to develop an SVM-based predictive model for banking systemic risk. Our paper is organized as follows. Section 2 provides the brief description of SVM theory. Section 3 elaborates a case study of 
an SVM-based prediction model for Chinese banking systemic risk. Section 4 draws conclusions.

\section{Support Vector Machine}

Based on statistical learning theory, Vapnik [15] put forward support vector machine. Its basic idea is to construct an optimal separating hyperplane with high classification accuracy [19]. A brief description of the SVM algorithm is provided as follows $[16,18,19]$.

Consider the training dataset $D=\left\{x_{i}, y_{i}\right\}_{i=1}^{M}$, where $x_{i} \in$ $R^{m}$ is an input vector and $y_{i} \in\{-1,1\}$ denotes a target label. In the linear separable case, SVM algorithm is to find an optimal separating plane $w \cdot x+b=0$. In the nonlinear separable case, a nonlinear function $\Phi(x)$ must be applied to map input space to a higher dimensional feature space, and the constrained optimization model of soft margin based on SVM is as follows [19]:

$$
\text { Minimize } \frac{1}{2} w^{T} w+C \sum_{i=1}^{M} \xi_{i}
$$

subject to

$$
\begin{gathered}
y_{i}\left[w^{T} \Phi\left(x_{i}\right)+b\right] \geq 1-\xi_{i} \quad(i=1,2, \ldots, M), \\
\xi_{i} \geq 0 \quad(i=1,2, \ldots, M),
\end{gathered}
$$

where $\xi_{i}$ is a slack variable and $C$ is a tuning parameter. By applying the Lagrangian technique to (2), we can obtain its dual problem as follows:

$$
\text { Maximize } \frac{1}{2} \alpha^{T} Q \alpha-e^{T} \alpha
$$

subject to

$$
\begin{gathered}
0 \leq \alpha_{i} \leq C \quad(i=1,2, \ldots, M), \\
y^{T} \alpha=0
\end{gathered}
$$

where $e^{T}$ is a vector of all ones, $Q$ is a positive semidefinite matrix, and $\alpha_{i}$ is Lagrange multiplier. The element $Q_{i j}$ of $Q$ is equal to $y_{i} y_{j} K\left(x_{i}, x_{j}\right)$, where $K\left(x_{i}, x_{j}\right)=\Phi\left(x_{i}\right)^{T} \Phi\left(x_{j}\right)$ is called kernel function. There are different kernel functions, such as linear, polynomial, and radial basis functions (RBF). Based on the above analysis, we can obtain the ultimate classifier function of SVM as follows:

$$
f(x)=\operatorname{sign}\left(\sum_{i=1}^{M} \alpha_{i} y_{i} K\left(x, x_{i}\right)+b\right) .
$$

\section{Prediction Model for Banking Systemic Risk}

In this section, we take the Chinese banking system as an example to construct an SVM-based prediction model for banking systemic risk and conduct empirical analysis based on the data of the Chinese banking system.

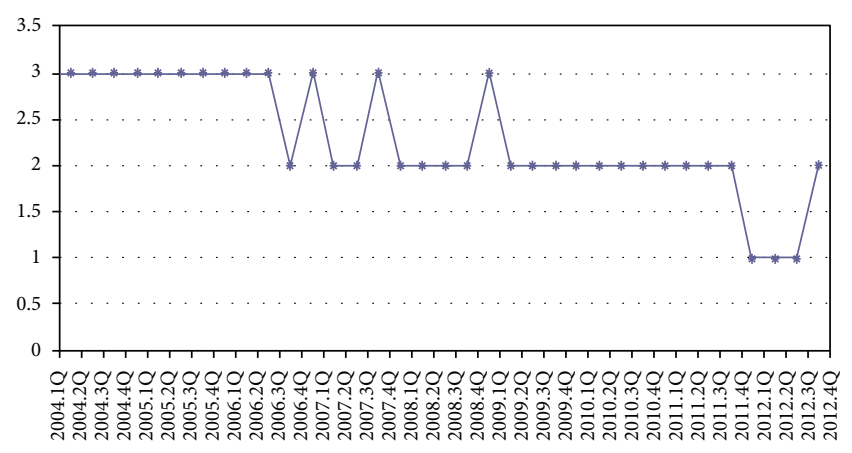

FIGURE 1: Classification result of levels of banking systemic risk from the first quarter of 2004 to the third quarter of 2012. In these Figures 1,2 and 3 represent respectively, safety, mild safety and mild unsafety.

3.1. Prediction Indicators for Banking Systemic Risk. Microprudential indicators cannot provide a systemic perspective on banking systemic risk, while macro-prudential indicators cannot provide distress warnings from individual banks. Recent financial crises show that interbank connections play an important role in propagation mechanisms of banking systemic risk. Thus, the prediction indicators for banking systemic risk should incorporate both Microprudential and macro-prudential perspectives, as well as the characteristics of interbank connections. Based on the relative studies [2023], prediction indicators and their prudential intervals for banking systemic risk in this paper are given in Table 1, where all indicators are processed chemotactically, $X_{i}(i=$ $1,2, \ldots, 7)$ are Microprudential indicators, $X_{j}(j=8,9,10)$ are indicators of interbank connections, and $X_{k}(k=11$, $12, \ldots, 17)$ are macro-prudential indicators.

3.2. Evaluation for Levels of Banking Systemic Risk. In light of the lack of data on levels of banking systemic risk in China, we adopt the principal component analysis to classify levels of banking systemic risk. The basic idea is as follows: constructing three critical value samples based on data of prediction indicators processed chemotactically in Table 1; conducting the principal component analysis on selected samples and the three critical value samples; classifying scores of selected experimental samples according to scores of the three critical value samples. In this paper, we select data of prediction indicators from the first quarter of 2004 to the third quarter of 2012 to collect the experimental data. By conducting the principal component analysis, we can obtain the levels of banking systemic risk, which is presented in Figure 1.

3.3. Empirical Analysis of Prediction Accuracy. In this section, we analyze the prediction accuracy of SVM and also compare its performance with those of back-propagation neural network (BPNN), multiple discriminant analysis (MDA), and logistic regression analysis (Logit). We take the data of prediction indicators from the first quarter of 2004 to the second quarter of 2008 as the training sample and the rest of the data as the testing sample. At the same time, we construct a safety sample based on critical values of the safety condition 
TABLE 1: List of prediction indicators for banking systemic risk.

\begin{tabular}{|c|c|c|c|c|}
\hline Indicator & Safety & Mild safety & Mild unsafety & Unsafety \\
\hline Capital adequacy ratio $\left(X_{1}\right)$ & $12 \% \leq X_{1}$ & $10 \% \leq X_{1}<12 \%$ & $8 \% \leq X_{1}<10 \%$ & $X_{1}<8 \%$ \\
\hline $\begin{array}{l}\text { Nonperforming loan ratio } \\
\left(X_{2}\right)\end{array}$ & $X_{2} \leq 2 \%$ & $2 \%<X_{2} \leq 3.5 \%$ & $3.5 \%<X_{2} \leq 5 \%$ & $5 \%<X_{2}$ \\
\hline $\begin{array}{l}\text { Proportion of a single } \\
\text { maximum loan }\left(X_{3}\right)\end{array}$ & $X_{3} \leq 6 \%$ & $6 \%<X_{3} \leq 8 \%$ & $8 \%<X_{3} \leq 10 \%$ & $10 \%<X_{3}$ \\
\hline Return on assets $\left(X_{4}\right)$ & $0.25 \% \leq X_{4}$ & $0.2 \% \leq X_{4}<0.25 \%$ & $0.2 \% \leq X_{4}<0.15 \%$ & $X_{4}<0.15 \%$ \\
\hline Cost-to-income ratio $\left(X_{5}\right)$ & $X_{5} \leq 20 \%$ & $20 \%<X_{5} \leq 28 \%$ & $28 \%<X_{5} \leq 35 \%$ & $35 \%<X_{5}$ \\
\hline Liquidity ratio $\left(X_{6}\right)$ & $45 \% \leq X_{6}$ & $35 \% \leq X_{6}<45 \%$ & $25 \% \leq X_{6}<35 \%$ & $X_{6}<25 \%$ \\
\hline Loan-to-deposit ratio $\left(X_{7}\right)$ & $X_{7} \leq 55 \%$ & $55 \%<X_{7} \leq 65 \%$ & $65 \%<X_{7} \leq 75 \%$ & $75 \%<X_{7}$ \\
\hline Leverage $\left(X_{8}\right)$ & $8 \% \leq X_{8}$ & $8 \% \leq X_{8}<6 \%$ & $6 \% \leq X_{8}<4 \%$ & $X_{8}<4 \%$ \\
\hline Interdependence $\left(X_{9}\right)$ & $X_{9} \leq 6 \%$ & $6 \%<X_{9} \leq 8 \%$ & $8 \%<X_{9} \leq 10 \%$ & $10 \%<X_{9}$ \\
\hline External linkages $\left(X_{10}\right)$ & $X_{10} \leq 1.8 \%$ & $1.8 \%<X_{10} \leq 2 \%$ & $2 \%<X_{10} \leq 2.2 \%$ & $2.2 \%<X_{10}$ \\
\hline $\begin{array}{l}\text { Year-on-year growth of } \\
\operatorname{GDP}\left(X_{11}\right)\end{array}$ & $\left|X_{11}-8 \%\right| \leq 1.5 \%$ & $1.5 \%<\left|X_{11}-8 \%\right| \leq 3 \%$ & $3 \%<\left|X_{11}-8 \%\right| \leq 4.5 \%$ & $4.5 \%<\left|X_{11}-8 \%\right|$ \\
\hline $\begin{array}{l}\text { Year-on-year growth of CPI } \\
\left(X_{12}\right)\end{array}$ & $\left|X_{12}-2 \%\right| \leq 2 \%$ & $2 \%<\left|X_{12}-2 \%\right| \leq 4 \%$ & $4 \%<\left|X_{12}-2 \%\right| \leq 6 \%$ & $6 \%<\left|X_{12}-2 \%\right|$ \\
\hline $\begin{array}{l}\text { Year-on-year growth of } \\
\text { fixed asset investment }\left(X_{13}\right)\end{array}$ & $\left|X_{13}-16 \%\right| \leq 3 \%$ & $3 \%<\left|X_{13}-16 \%\right| \leq 6 \%$ & $6 \%<\left|X_{13}-16 \%\right| \leq 9 \%$ & $9 \%<\left|X_{13}-16 \%\right|$ \\
\hline $\begin{array}{l}\text { Year-on-year growth of } \\
\text { national real estate index } \\
\left(X_{14}\right)\end{array}$ & $\left|X_{14}\right| \leq 1.5 \%$ & $1.5 \%<\left|X_{14}\right| \leq 3 \%$ & $3 \%<\left|X_{14}\right| \leq 4.5 \%$ & $4.5 \%<\left|X_{14}\right|$ \\
\hline $\begin{array}{l}\text { Volatility of the Shanghai } \\
\text { index }\left(X_{15}\right)\end{array}$ & $\left|X_{15}\right| \leq 10 \%$ & $10 \%<\left|X_{15}\right| \leq 15 \%$ & $15 \%<\left|X_{15}\right| \leq 20 \%$ & $20 \%<\left|X_{15}\right|$ \\
\hline $\begin{array}{l}\text { Ratio of growth of M2 to } \\
\text { growth of GDP }\left(X_{16}\right)\end{array}$ & $X_{16} \leq 1.5$ & $1.5<X_{16} \leq 2.2$ & $2.2<X_{16} \leq 3$ & $3<X_{16}$ \\
\hline $\begin{array}{l}\text { Volatility of benchmark } \\
\text { lending rates }\left(X_{17}\right)\end{array}$ & $\left|X_{17}\right|=0$ & $0<\left|X_{17}\right| \leq 0.2 \%$ & $0.2 \%<\left|X_{17}\right| \leq 0.4 \%$ & $0.4 \%<\left|X_{17}\right|$ \\
\hline
\end{tabular}

into the training sample, because of the lack of safety samples in the training sample. Therefore, the size of the training sample is equal to 19 , and the sizes of the testing sample is equal to 17. In case of BPNN, the rest data is split into the validation sample and the testing sample, and the size of the validation sample and the testing sample are 4 and 13, respectively.

3.3.1. Prediction Accuracy of SVM. Construction of prediction models for banking systemic risk based on SVM is to choose the kernel function and the values of model parameters. In this paper, the radial basis function (RBF) is used as the basic kernel function of SVM, because it usually gets better results than other kernel functions [24]. There are two parameters associated with RBF kernels: $C$ and $g$, playing a crucial role in the performance of SVM. Therefore, improper selection of these two parameters can cause overfitting or underfitting problems. In this paper, we determine the values of parameters $C$ and $g$ by using Grid Search, Genetic Algorithms, and Particle Swarm Optimization.

According to the above method, we first analyze prediction accuracy of prediction models for banking systemic risk based on SVM. Based on the above data, we can obtain values of optimal parameters $C$ and $g$ for SVM model by Grid Search, Genetic Algorithms, and Particle
TABLE 2: The prediction accuracy of SVM.

\begin{tabular}{lccc}
\hline & Grid Search & $\begin{array}{c}\text { Genetic } \\
\text { Algorithms }\end{array}$ & $\begin{array}{c}\text { Particle Swarm } \\
\text { Optimization }\end{array}$ \\
\hline Training sample & $100 \%$ & $100 \%$ & $100 \%$ \\
Testing sample & $94.12 \%$ & $88.24 \%$ & $88.24 \%$ \\
\hline
\end{tabular}

Swarm Optimization. Figures 2, 3, and 4 report, respectively, the results of Grid Search, Genetic Algorithms, and Particle Swarm Optimization. As we observe from Figures 2, 3 and 4, the optimal parameters $(C, g)$ of Grid Search, Genetic Algorithms, and Particle Swarm Optimization are $(1.74,0.57),(1.68,0.74)$, and $(2.51,0.43)$, respectively. After the optimal parametes $(C, g)$ are found, we can obtain that the best prediction accuracy of the testing sample is $94.12 \%$. The performance of SVM under the above mentioned three methods is summarized in Table 2.

3.3.2. Comparison of Prediction Accuracy of SVM, BPNN, $M D A$, and Logit. Back-propagation neural network (BPNN), multiple discriminant analysis (MDA), and logistic regression analysis (Logit) are widely applied methods for prediction. Therefore, in this paper, we compare the prediction accuracy of SVM with those of BPNN, MDA, and 


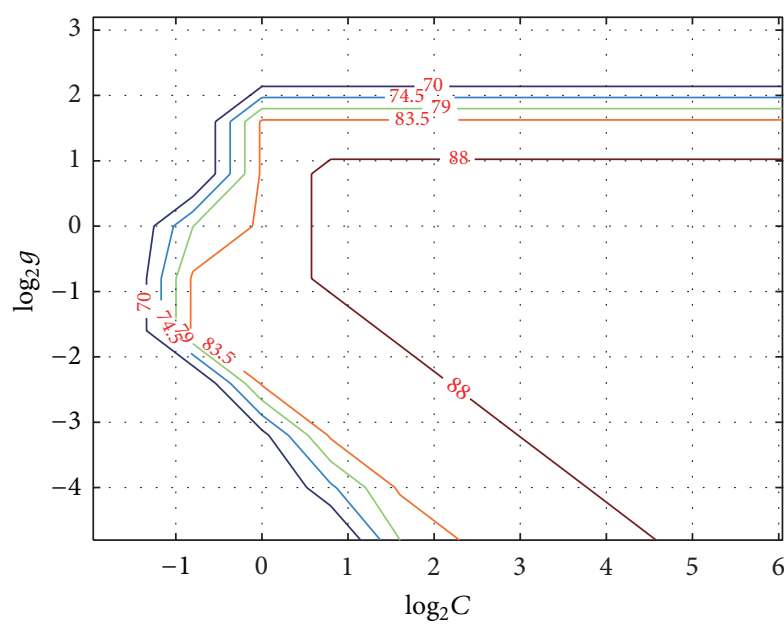

Figure 2: Contour lines of Grid Search. Best $C=1.74, g=0.57$, $\mathrm{CV}$ accuracy $=89.47 \%$.

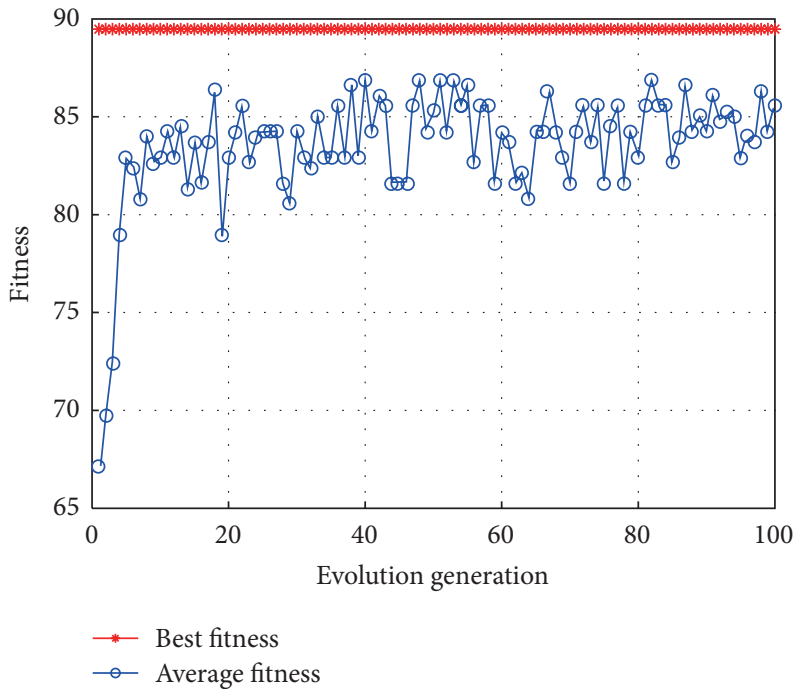

FIGURE 3: Fitness curve of Genetic Algorithms (termination of generation $=100$, pop $=20$ ). Best $C=1.68, g=0.74$, and CV accuracy $=89.47 \%$.

Logit. In case of BPNN, a three-layer fully connected backpropagation neural network is used as a benchmark; $5,10,15$, 20,25 , and 30 hidden nodes in the hidden layer are analyzed; the maximum number of learning epochs is set to 1000 ; the learning rate is set to 0.01 ; the momentum term is set to 0.95 ; the activation function of the hidden layer and the output layer are, respectively, Tansig and Purelin; the training function is Trainlm. According to parameter adjustment, we can obtain that the best prediction accuracy of the testing sample is found when the number of hidden nodes is 20 . The prediction accuracy of the testing sample, the training sample, and the validation sample is $84.62 \%, 100 \%$, and $100 \%$, respectively.

Table 3 summarizes the best prediction performance of SVM, BPNN, MDA, and Logit in the training sample and the testing sample. From Table 3, we can see that SVM

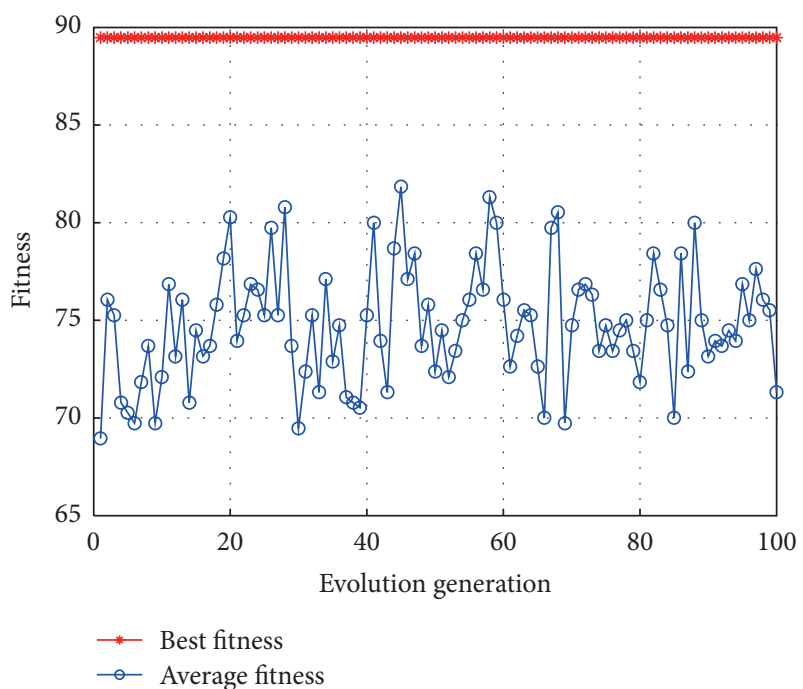

FIgURE 4: Fitness curve of Particle Swarm Optimization (termination of generation $=100$, pop $=20, c_{1}=1.50$, and $c_{2}=1.70$ ). Best $C=2.51, g=0.43$, and CV accuracy $=89.47 \%$.

TABLE 3: The best prediction accuracy of SVM, BPNN, MDA, and Logit.

\begin{tabular}{lcccc}
\hline & SVM & BPNN & MDA & Logit \\
\hline Training sample & $100 \%$ & $100 \%$ & $94.74 \%$ & $100 \%$ \\
Testing sample & $94.12 \%$ & $84.62 \%$ & $76.47 \%$ & $76.47 \%$ \\
\hline
\end{tabular}

TABLE 4: McNemar values ( $P$ values) for the pairwise comparison of performance.

\begin{tabular}{lccc}
\hline & BPNN & MDA & Logit \\
\hline SVM & $3.37(0.064)$ & $11.12(0.001)$ & $10.32(0.001)$ \\
BPNN & & $1.53(0.175)$ & $1.29(0.122)$ \\
MDA & & & $0.042(1.000)$ \\
\hline
\end{tabular}

outperforms BPNN, MDA, and Logit: 9.5\%, 17.65\% and $17.65 \%$, respectively, for the testing sample. In addition, we conduct the McNemar test to examine whether SVM significantly outperforms the other three methods. Table 4 shows the results of the McNemar test. As shown in Table 4, SVM outperforms BPNN at $10 \%$ statistical significance level, and SVM outperforms MDA and Logit at 5\% statistical significance level. However, Table 4 also shows that the prediction performances of BPNN, MDA, and Logit do not significantly differ from each other. The above result shows that support vector machine has certain advantages for the prediction of banking systemic risk with the complex nonlinear characteristics.

\section{Conclusion}

In this paper, we apply SVM to predict banking systemic risk. To validate the prediction performance of this approach, we conduct a case study of an SVM-based prediction model for Chinese banking systemic risk. First, we construct 
the prediction indicators for banking systemic risk from both Microprudential and macro-prudential perspectives, as well as the characteristics of interbank connections. Second, we adopt the principal component analysis to classify levels of banking systemic risk. Based on the above analysis, we conduct empirical analysis of prediction accuracy of the SVM-based prediction model for banking systemic risk. The results of empirical analysis show the capability, accuracy, and high efficiency of the SVM-based prediction model. In addition, compared with the BPNN-based prediction model, multiple discriminant analysis, and logistic regression analysis, the SVM-based prediction model shows superior prediction power. With these results, we claim that SVM can serve as a promising alternative in the prediction of banking systemic risk.

\section{Acknowledgments}

This research is supported by NSFC (no. 71071034, no. 71201023), NBRR (no. 2010CB328104-02), and Humanities and Social Science Youth Foundation of the Ministry of Education of China (no. 12YJC630101).

\section{References}

[1] J. A. Frankel and A. K. Rose, "Currency crashes in emerging markets: an empirical treatment," Journal of International Economics, vol. 41, no. 3-4, pp. 351-366, 1996.

[2] G. L. Kaminsky and C. M. Reinhart, "The twin crises: the causes of banking and balance-of-payments problems," American Economic Review, vol. 89, no. 3, pp. 473-500, 1999.

[3] A. Demirgüç-Kunt and E. Detragiache, "Monitoring banking sector fragility: a multivariate logit approach," World Bank Economic Review, vol. 14, no. 2, pp. 287-307, 2000.

[4] E. Hanschel and P. Monnin, "Measuring and forecasting stress in the banking sector: evidence from Switzerland," in Investigating the Relationship between the Financial and Real Economy, BIS Papers no. 22, 2005.

[5] E. P. Davis and D. Karim, "Comparing early warning systems for banking crises," Journal of Financial Stability, vol. 4, no. 2, pp. 89-120, 2008.

[6] M. Oet, R. Eiben, T. Bianco, D. Gramlich, S. Ong, and J. Wang, "SAFE: an early warning system for systemic banking risk," in Proceedings of the 24th Australasian Finance and Banking Conference, SSRN, 2011.

[7] C. S. Lin, H. A. Khan, R. Y. Chang, and Y. C. Wang, "A new approach to modeling early warning systems for currency crises: can a machine-learning fuzzy expert system predict the currency crises effectively?" Journal of International Money and Finance, vol. 27, no. 7, pp. 1098-1121, 2008.

[8] R. Duttagupta and P. Cashin, "Anatomy of banking crises: a Binary classification tree approach," IMF Working Paper 08/93, 2008.

[9] D. Karim, "The use of Binary recursive trees for banking crisis prediction," Tech. Rep., Brunel University Department of Economics and Finance Working Paper, Brunel University, London, UK, 2008.

[10] L. Laeven and F. Valencia, "Systemic banking crises: a new database," IMF Working Papers, 2008.
[11] M. L. Duca and T. A. Peltonen, "Assessing systemic risks and predicting systemic events," Journal of Banking Finance, 2012.

[12] G. Iori, G. de Masi, O. V. Precup, G. Gabbi, and G. Caldarelli, "A network analysis of the Italian overnight money market," Journal of Economic Dynamics and Control, vol. 32, no. 1, pp. 259-278, 2008.

[13] D. O. Cajueiro and B. M. Tabak, "The role of banks in the Brazilian interbank market: does bank type matter?" Physica A: Statistical Mechanics and Its Applications, vol. 387, no. 27, pp. 6825-6836, 2008.

[14] C. P. Georg, The Effect of the Interbank Network Structure on Contagion and Common Shocks, Discussion Paper Series 2: Banking and Financial Studies, 2011.

[15] V. N. Vapnik, Statistical Learning Theory, Adaptive and Learning Systems for Signal Processing, Communications, and Control, John Wiley \& Sons, New York, NY, USA, 1998.

[16] J. J. Ahn, K. J. Oh, T. Y. Kim, and D. H. Kim, "Usefulness of support vector machine to develop an early warning system for financial crisis," Expert Systems with Applications, vol. 38, no. 4, pp. 2966-2973, 2011.

[17] Z. Xie, I. Lou, W. K. Ung, and K. M. Mok, "Freshwater algal bloom prediction by support vector machine in macau storage reservoirs," Mathematical Problems in Engineering, vol. 2012, Article ID 397473, 12 pages, 2012.

[18] G. Chen, Y. Zuo, J. Sun, and Y. Li, "Support-vector-machinebased reduced-order model for limit cycle oscillation prediction of nonlinear aeroelastic system," Mathematical Problems in Engineering, vol. 2012, Article ID 152123, 12 pages, 2012.

[19] J. Sun and H. Li, "Financial distress prediction using support vector machines: ensemble vs individual," Applied Soft Computing, vol. 12, no. 8, pp. 2254-2265, 2012.

[20] M. Arena, "Bank failures and bank fundamentals: a comparative analysis of Latin America and East Asia during the nineties using bank-level data," Journal of Banking and Finance, vol. 32, no. 2, pp. 299-310, 2008.

[21] A. Agresti, P. Baudino, and P. Poloni, "The ECB and IMF indicators for the macro-prudential analysis of the banking sector: a comparison of the two approaches," ECB Occasional Paper, 2008.

[22] C. M. Reinhart and K. S. Rogoff, This Time Is Different: Eight Centuries of Financial Folly, Princeton University Press, Princeton, NJ, USA, 2009.

[23] International Monetary Fund (IMF), Global Financial Stability Report, IMF, Washington, DC, USA.

[24] J. H. Min and Y. C. Lee, "Bankruptcy prediction using support vector machine with optimal choice of kernel function parameters," Expert Systems with Applications, vol. 28, no. 4, pp. 603$614,2005$. 


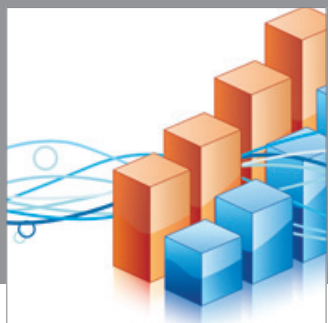

Advances in

Operations Research

mansans

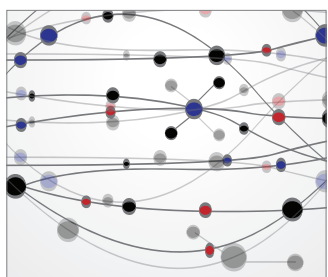

The Scientific World Journal
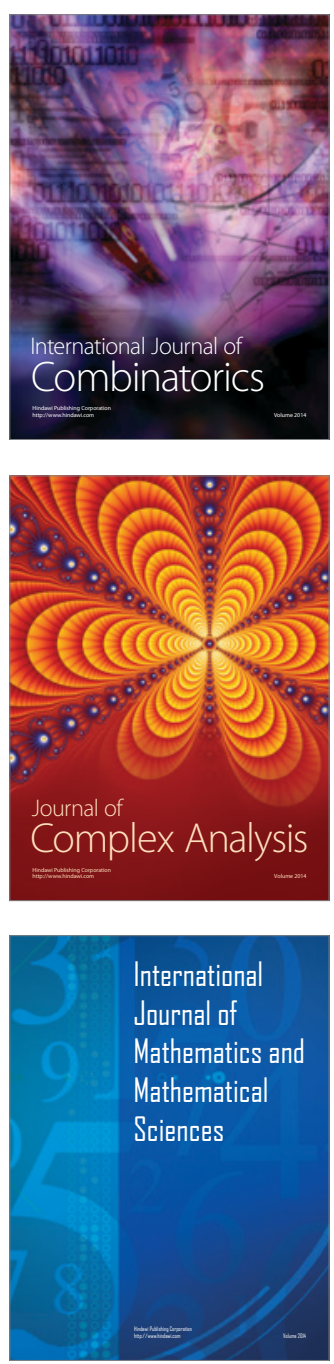
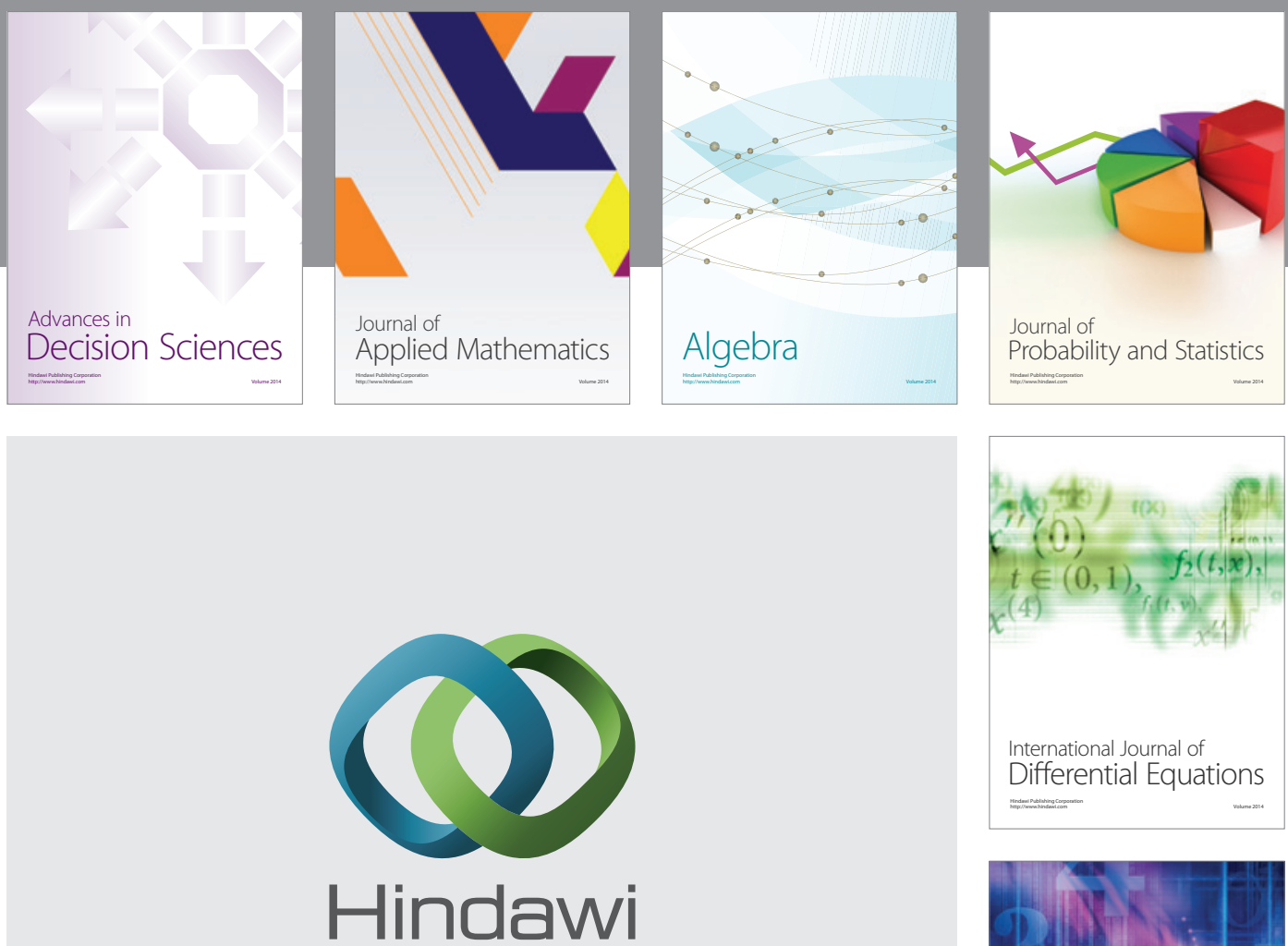

Submit your manuscripts at http://www.hindawi.com
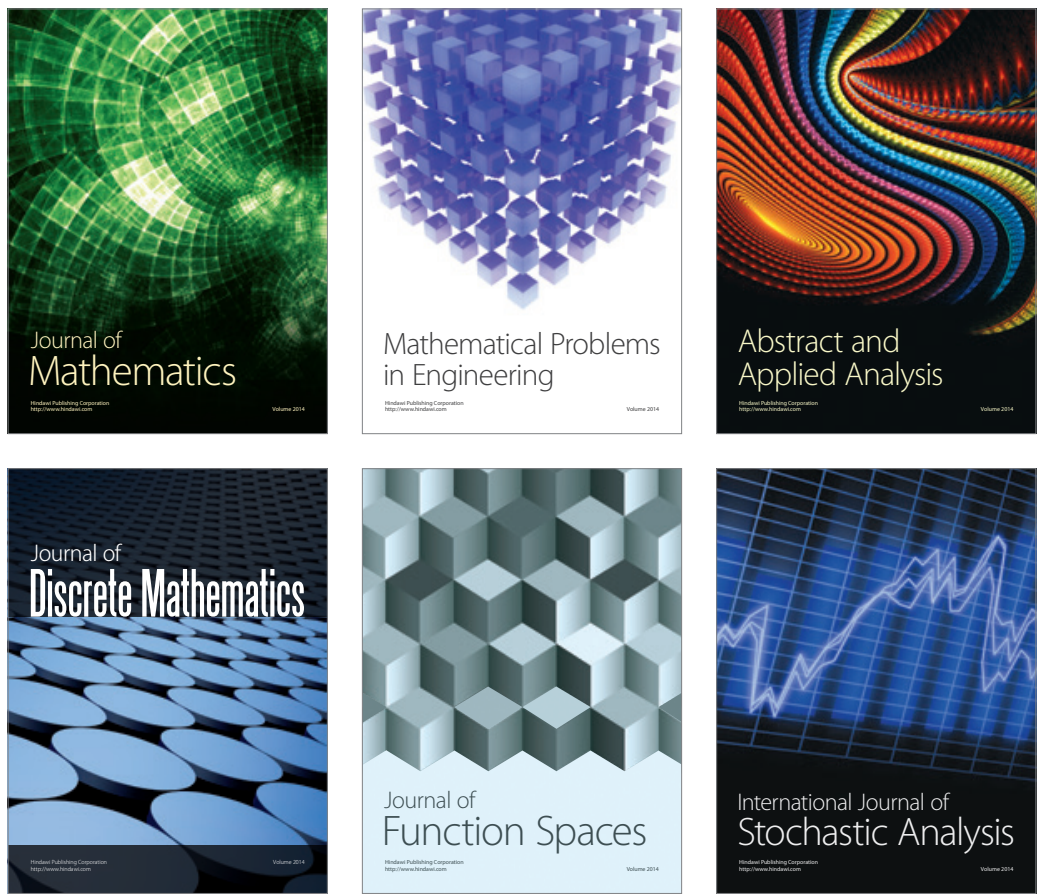

Journal of

Function Spaces

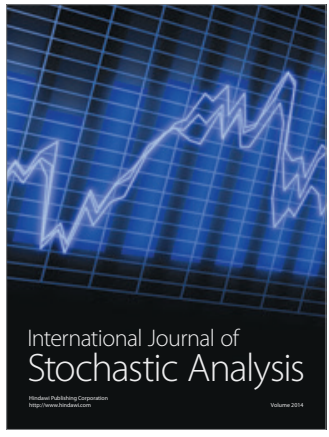

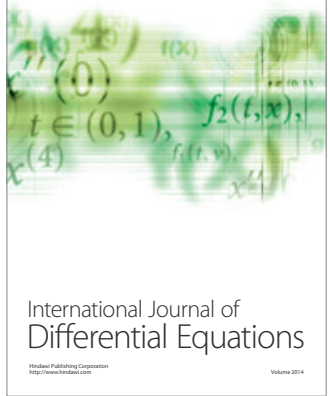
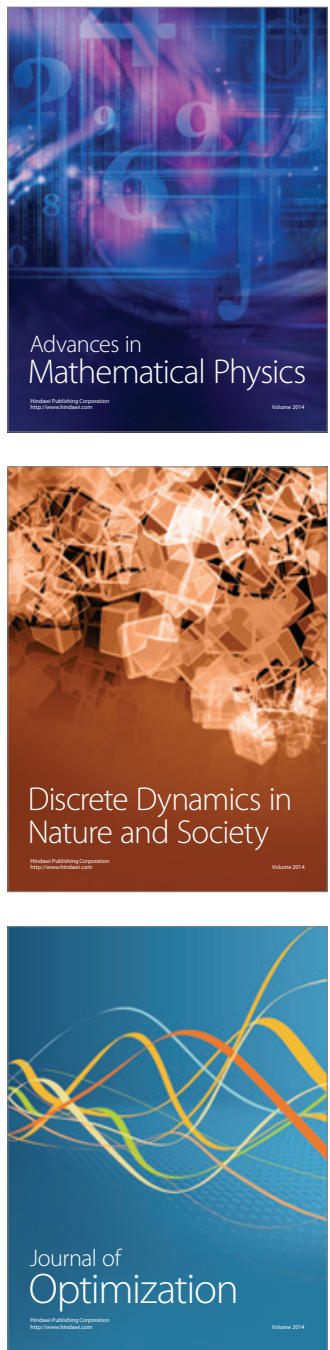